\title{
1. Introduction Toshiaki Tachibanaki
}

\section{MOTIVATIONS OF THE BOOK AND SEVERAL FEATURES OF SOCIAL SECURITY SYSTEMS IN JAPAN}

Historically, Japan has not been a welfare state, which is a country where the public sector (central government and/or local governments) provides citizens with considerable welfare provision. This can be clearly seen in Table 1.1, which gives an international comparison of the share of social security benefits over national incomes, and the rate of tax revenues and social security contributions. The table shows that Japan is in the lowest group together with the United States, where it is regarded as a typical nonwelfare state country. Note that Japan is even somewhat lower than the United States.

Why has Japan been seen as a typical example of the non-welfare state?

Table 1.1 Rate of social security benefits over national incomes ( $A$ ), and rate of tax revenues and social security contributions over GDP (B) $(\%)$

\begin{tabular}{|c|c|c|c|c|c|c|}
\hline & \multicolumn{2}{|c|}{ A } & \multicolumn{4}{|c|}{ B } \\
\hline & & & & Total rates & Taxes & $\begin{array}{l}\text { Social security } \\
\text { contributions }\end{array}$ \\
\hline \multirow[t]{2}{*}{ Japan } & 1993 & 15.2 & 2002 & 38.3 & 22.9 & 15.5 \\
\hline & 1997 & 17.8 & & & & \\
\hline USA & 1992 & 18.7 & 1997 & 37.0 & 26.2 & 9.8 \\
\hline UK & 1993 & 27.2 & 1999 & 50.0 & 40.0 & 10.0 \\
\hline Germany & 1993 & 33.3 & 1999 & 56.7 & 25.7 & 31.0 \\
\hline France & 1993 & 37.2 & 1999 & 66.1 & 40.6 & 25.5 \\
\hline Sweden & 1993 & 53.4 & 1999 & 75.4 & 55.8 & 19.7 \\
\hline
\end{tabular}

Sources: (A) National Institute of Social Security and Population, Social Security Benefits, Tokyo 2000. (B) Ministry of Welfare and Labor, White Paper, Tokyo 2002. 
There are four possible reasons. The first is that families have traditionally been responsible for providing for their members. This is due partly to an East-Asian cultural heritage which emphasizes family ties. Second, enterprises, in particular larger ones recognized the benefit of making welfare provision available to their employees - in short, there was an economic incentive. Good economic conditions due to their higher productivities cannot be ignored as an additional cause. Third, the main goal of the government during the post-war period was to promote strong industrialization and thus higher economic growth. Thus, the government did not concern itself over people's welfare, and the private sector (for example, families and large enterprises) has responded to the government attitude. Fourth, Japan did not have an ageing population in the 1960s and 1970s, when strong industrialization and rapid economic growth was achieved. Also, life expectancy was not as high at that time, although it is now one of the highest in the world. These phenomena imply that the demand for welfare services such as old-age pensions, medical care, home care for the elderly and so on was relatively less, although it is very high currently because of the ageing trend in population structures.

Tachibanaki (1996a and b, 2000, 2002, 2003) has discussed these issues fully, in particular the reasons why families and larger enterprises were committed to making welfare provision. It must be emphasized, however, that citizens' and families' attitudes towards this phenomenon is currently undergoing a serious transition process; in other words, the degree of family ties and thus mutual help among family members is weakening considerably. At the same time, industrial sectors benefited from families' commitment to welfare provision, and from the relatively lower financial burdens of employers' contributions to various social security systems in order to achieve good economic performances. However, industrial sectors are still suffering from the current serious recession which has continued for the past ten years, and are reluctant to accept a possible increase in the financial burden of employers' contribution to the social security system during the current ageing trend. In sum, various changes in both family structure and enterprise conditions demand a reconsideration of Japanese welfare provision systems.

The purpose of this book is to examine how social security systems are facing a serious transition process in Japan as described above, and to propose various policy recommendations. It does not address general issues which would be useful to an understanding of the entire welfare provision as a whole, but rather examines various components separately, such as the public pension, the enterprise or occupational pension, medical care, child care, and a barrier-free infrastructure for the disabled. A few chapters, however, such as those by Tachibanaki (Chapter 2) and Yagi (Chapter 11), 
touch on general issues such as the Japanese social security system as a whole, and the concept of capability according to Amartya Sen.

One important feature of this book is that contributions have been made by both Japanese and non-Japanese specialists. Japanese authors, needless to say, know the system well, and thus are able to investigate issues in depth regarding the advantages and disadvantages of the system. Non-Japanese authors may not be as familiar with the system, but they are able to evaluate it without prior prejudice, using their own countries' experience for a comparative perspective. I hope that readers can appreciate the subtle differences between Japanese and non-Japanese writers, all of whom are leading specialists in their field.

Before presenting a summary discussion of each chapter, several features of the Japanese systems of public pension, enterprise pension, medical care, child care and a barrier-free infrastructure for the disabled are examined very briefly as a reference point for readers.

\subsection{Public Pension}

There are two elements to this pension: the first is the basic part which pays a flat rate to each retiree, and the second is the proportional part. One-third of the basic part is financed by tax revenues, and the remaining two-thirds by social insurance contributions. The second part functions principally as a pay-as-you-go scheme with a modified version of a funded scheme. The serious ageing trend demands radical reforms in both payment structures and financing methods.

There are three different proposals. First, modifying from a pay-as-yougo to a funded scheme, which includes a reduction in benefits and an increase in contributions. Second, keeping the contribution rate at 20 percent in the final stage, and raising it gradually every year before the final stage of 20 percent. The benefit level would fluctuate according to each year's budget. This is the Swedish type of reform, and the current government seems to prefer it. Third, introducing drastic tax measures instead of social security contributions, and maintaining the current benefit level.

\subsection{Enterprise Pension}

Historically, enterprise pension programs evolved from a one-off retirement payment, which was the system commonly used by larger enterprises. Payment was made at the time of retirement to a life-time employee. There was a gradual shift from a one-off lump sum to an annual pension payment for a limited duration. The basic scheme, therefore, has been a defined benefit (DB) type. Since the influence of the US-type defined contribution 
(DC) plan is strong, a large number of enterprises contemplate introducing a defined contribution type, or shifting from the former to the latter, or introducing a hybrid of the two.

There are several reasons and motivations for these policy reforms. First, there is a significant degree of uncertainty associated with the future course of the public pension program. It would be necessary to rely on enterprise pensions in the future, if the benefit level of public pensions were cut. Second, the ageing trend within each enterprise would result in financial difficulty in the management of an enterprise pension program. Third, the current low interest rate and low return on equities would also lead to financial difficulty for enterprise pension programs in particular when a defined benefit plan is the basic scheme. Employers would have to contribute significantly in such a case in order to improve the financial situation, and they hope, naturally, to avoid having to make such contributions.

\subsection{Medical Care (or Insurance)}

The most important feature of the medical insurance system is the existence of a large number of independent insurance programs, which are differentiated by participants' age, occupation, enterprise size and so on. Since age structure, earnings capacity, financial conditions of employers and so on vary so widely among the programs, the rates of benefits and contributions, and financial conditions also differ considerably from program to program. Some internal financial transfers among various programs have been made to help financially troubled programs. This is an imperfect arrangement, and thus more reliable reforms are called for.

Another important feature is that government regulations concerning the medical sector and health insurance programs are strict. In other words, patients and medical insurance participants are unable to express their hopes and demands effectively, and insurers cannot play a significant role. Another obstacle is the strength of medical doctors' and pharmacy associations. Asymmetrical information between specialists and patients, of course, is one of the causes of the difficulty in the medical insurance system. Far-reaching policy reforms are necessary.

\subsection{Child-care System}

A system of leave for child care has been uncommon because married women have traditionally been responsible for taking care of babies and children at home. Many women retire from the labor market when they get married, or give birth. They stay at home to take care of the children, and return to working activities after their children have grown up. Of course, 
there have always been a certain number of women who continue to work and combine it with marriage and child-bearing.

There is now a strong demand for introducing and strengthening a childcare leave system for the following reasons. First, many married women want to continue working without any interruptions for marriage and child care. Second, the current birth rate is very low at 1.34 births per woman. This low rate is regarded as a serious problem by the majority of concerned people. It is believed that one of the causes is insufficient provision for childcare leave, although there are many other concerns. There is a consensus that society should take care of children. The issue is, 'Who takes the initiative, who bears the financial burden, and how are children cared for?'.

\subsection{Barrier-free Infrastructure for the Disabled}

Barrier-free infrastructure systems have been underdeveloped for various reasons. First, the economy and society regarded strong industrialization as the top priority during the entire post-war period. Consequently, no serious attention has been paid to the disabled, and thus public expenditure on easy accessibility and quality of life has for them been quite limited. Second, many people felt that families and relatives should be responsible for providing them with various services. This idea came from the general understanding that families were responsible for providing the needy with various welfare services, and this also included the elderly disabled. It is now time to reconsider such a limited infrastructure, and society has started to recognize it.

\section{SUMMARY OF THE CONTENT}

In Chapter 2, Tachibanaki is concerned with the problem of pension programs. He presents two major reforms in social security in Japan. The first one is to switch the public pension system from the current pay-as-you-go insurance principle to the tax financing method at least for the basic part of the pension benefit. More concretely, it is recommended that progressive consumption tax or progressive expenditure tax is introduced. The second reform is to allow and even encourage firms to withdraw from welfare provision programs. Tachibanaki examines the present status of social security systems in Japan, and concludes that Japan is not a welfare state. The major providers are families and firms, particularly large firms. The chapter also discusses various issues of public pension and enterprise pension reform in the advanced countries, including privatization, efficiency-equity trade-off, tax incidence, and so on. It presents a scheme for reform in the 
public pension system, and a recommendation of withdrawal from firms' contribution to welfare provisions. It is proposed that such reforms and recommendations are useful to maintain the standard of living for the aged in an uncertain world, and improve the economic prosperity of firms which are currently in serious recession and facing acute competition internationally.

In Chapter 3, Aaron and Harris are concerned with uncertainty in public pension programs because the balance between pension contributions and benefits varies considerably because of uncertainty. Demographic uncertainty is, in particular, crucial under pay-as-you-go or partial-reverse financing because changes in fertility and mortality rates and other related variables affect both revenues and benefits in view of the long-run contracts of the system. One way to deal with these demographic uncertainties is to introduce indexed pensions and wages, and indeed many countries have introduced them. Aaron and Harris evaluate various indexing methods such as 'retrospective' indexing based on past changes in wages and prices, and 'prospective' indexing based on anticipated deviations of key variables from expected values. Also, other possible forms of indexing on labor force participation, productivity growth and so on in addition to traditional demographic variables are evaluated for both DB and DC plans. One attractive feature of their study is to evaluate the situation in both the United States and Japan. They conclude that indexing with respect to projections is technically problematic, which is understood as political rather than economical. This means that economists cannot make well-informed decisions on the timing and magnitude of indexing. Bearing this in mind, it is questionable whether a 'correct' political decision is possible.

Miles and Cerny (Chapter 4), present a comprehensive study on public pension programs, which includes a rigorous simulation study based on their economic model for Japan, and concrete policy recommendations. Their model is complex, and of a stochastic general equilibrium type. Emphasis is placed on uncertainty associated with labor income, returns on financial assets, efficiency in annuity markets, probabilities of surviving and so on. The model is a significant extension of the Auerbach-Kotlikoff model. The simulation results suggest several useful implications for Japan. For example, a long-run implication of a switch from a pay-as-you-go scheme to much greater reliance on a funded scheme is prudent because an increase in consumption and welfare for future generations would be considerable. This is provided through a higher personal saving rate, and thus a higher capital-labor ratio. The extent of financial risk or return on various financial assets is crucial in their exercise. One important finding is that there would be no intergenerational income transfers if the timing of contributions and of receiving benefits were adhered to rigorously. Also, there 
was no indication that reform would have any adverse distributional consequences. In sum, Miles and Cerny proposed that Japan should switch from a pay-as-you-go to a funded scheme in the management of public pensions.

In Chapter 5, Ohtake and Yamaga examine the effect of a public pension on labor supply. More specifically, they analyze the impact of the old-age pension system for active employees on the employment behavior of the elderly using the difference-in-differences method and the estimation of dynamic labor supply models. Data were obtained from 'Surveys on the Employment of Older Persons'. Both the difference-in-differences method and the estimated dynamic labor supply models show that the old-age pension system for active employees influenced the supply of workers in their early sixties (60 to 65 years of age). Effects of the reform of the system in 1995 are analyzed. The difference-in-differences method revealed that the reform affected the decision of whether to work, especially for elderly persons on a small pension, but did not affect working hours. The estimated dynamic labor supply models revealed no significant marginal tax rate effects of the pension system around 1995. The wage elasticities, which were estimated by pooling data for 1988, 1992, and 1996, were relatively high, ranging from 0.2 to 0.6 . Since the ageing trend implies that labor supply will be limited in future, it causes a slower economic growth rate. It is expected that the aged labor force will continue to work if they remain in good health. This would also alleviate a serious shortfall in the public pension budget. These findings should be borne in mind when policy reforms of the public pension program are being considered.

In Chapter 6, Clark and Mitchell compare both the public pension system and the enterprise (or company) pension program in the United States and Japan. Emphasis is placed on the enterprise pension program, and one of the objectives of such a comparison is to highlight several advantages in the US program and to suggest that some of these can be useful for policy reforms in Japan. The authors compared various institutional settings of enterprise pension programs, historical developments, their economic motivations, both employers' and employees' views and preferences on pension programs and so on. Emphasis is placed on a comparison between a DB plan and a DC plan for both the United States and Japan. Clark and Mitchell recommended that Japan should adopt the UStype DC plan in view of three success stories: first, the US regulatory and tax policies (the famous $401(\mathrm{k})$ ) were successful; second, changes in the composition of the US labor force and industrial relations favored a DC plan; and third, the US economy has recently been buoyant. Finally, they evaluated the 2001 legislation in Japan which approved a DC plan; they found that it was a 'big-bang' reform that would convert Japanese workers from savers to investors. 
In Chapter 7, Piggott, Purcal and Williams are concerned with Japanese asset allocations, and evaluate whether different financial investment strategies and activities produce considerably different outcomes in pension benefits. This kind of simulation is quite important because in the past households and even financial institutions adopted a fairly risk-averse attitude to investment; quite simply, they preferred the concept of safety to that of risk. After examining and reviewing various theoretical financial investment theories, Piggott, Purcal and Williams choose the following four investment strategies as the fund management formula for a DC plan in an enterprise (occupational) pension program: (i) an all-equities strategy at the Nikkei, (ii) a division strategy between stocks and bonds, (iii) a long-term phased strategy in which the proportion of the portfolio invested in stocks is gradually reduced over the life cycle, and (iv) a safe strategy in which all contributions and earnings are held in short-term bills. Their comprehensive simulation, which covers the past 30 years, suggests that, based on a simple stochastic model of investment return innovations, increasing the sophistication of the investment strategy generates outcomes, or distributions of outcomes, which dominate those implied by simple constantproportions positions. They recommend that Japanese investors should be more sophisticated in order to enjoy higher pension benefits under a DC plan.

Iwamoto (Chapter 8), discusses past national medical-care expenditure and its possible future path. It is an important subject because the ageing trend will increase medical costs in the future. About 30 percent of past growth was due to population ageing and the remaining 70 percent to technological change. Technical progress in the medical sector is rapid, and this has contributed to prolonging life expectancy considerably. Medical expenditure will increase by 40 percent in 30 years due to population ageing. The second half of the chapter focuses on a reform of health insurance for the elderly, and presents some policy recommendations. One of the most serious problems in the health-care market is that virtually nobody evaluated or attempted to improve the quality of medical services. It is not clear whether the rising medical costs are a result of waste or of necessity. It has been suggested that the government and the medical doctors' association colluded to maximize their regulation rents. A desirable direction of reform is that rather than relying on the government (that is, the regulator) and the doctors' association, the insurers will play a more active role in the healthcare market as informed agents for patients. Since the public sector has dominated the health insurance business, large-scale outsourcing of the health insurance business to the private sector should be promoted.

In Chapter 9, Ohkusa examines one of the most important current policy issues in Japan: its very low birth rate. One of the useful tools is to intro- 
duce and strengthen the child-care system. Ohkusa uses a new technique, 'conjoint analysis', which enables economists to estimate changes in the birth behavior under several alternative and hypothetical conditions. Several conditions were controlled, and additional economic and social variables were taken into account. The empirical results show that increasing child-care leave by one year increases the mean number of children by $0.12-0.14$. Income support during child-care leave also has a positive effect on fertility but a 10 percent improvement in the replacement rate of only 0.04 children. The condition of admission to the day-care service has a significant effect: the 'waiting list' cases decrease by $0.34-0.39$ and the 'very difficult' cases decrease by $0.52-0.58$ in comparison with the 'easy' cases. Financial rewards for bearing children have a positive effect, and increasing them by $¥ 34-40$ thousand boosts the average number of children in a family by 0.1 .

In Chapter 10, Kawaguchi examines the child-care leave system, which might encourage married women to return to work. According to Kawaguchi, problems with the current system are as follows: the atmosphere in the workplace is not sympathetic to those who wish to take childcare leave; the amount of benefit for such leave is small; there is no guarantee for those who take leave that they can return to the same job; casual workers are not eligible for leave; and wages may decline after taking leave. He shows that the interruption of women's careers after childbirth was the biggest cause of the large gender wage gap. However, an econometric analysis shows that the immediate wage reduction after taking childcare leave is not significant, but the opportunity of off-the-job training declines significantly later. The last result should result in a large wage reduction. Kawaguchi examines various institutional child-care leave systems, and evaluates them carefully. He concludes that we need a more comprehensive child-care benefit system which supports the harmonization of work and family. The proposed child-care benefit system shares the risk of raising children, and changes the traditional gender division of labor by encouraging male as well as female workers to take child-care leave. He suggests that firms should take strong action to support female employees taking leave, and that the government should endorse such actions.

Finally, in Chapter 11, Yagi investigates the rate of social infrastructure in an ageing society where there are a large number of disabled people. Before presenting his theoretical and empirical discussions, he raises the importance of the concept of 'capability', after Amartya Sen, and suggests that the capabilities of the disabled differ greatly depending upon how well accessibility to services is implemented. Yagi presents a theoretical model which analyzes the effect of introducing barrier-free infrastructure into a society where there are two types of people, non-disabled and disabled. The 
social optimization procedure for public expenditure and tax revenue is examined, and the conclusion is that the government should invest more than the amount indicated by residents, including the able-bodied. Yagi conducted his own survey on this issue, and presents several useful findings based on the contingent valuation method. Among them, it is proposed that able-bodied people have a strong feeling of responsibility for improving accessibility for the disabled. Also, some attempts are made to estimate the willingness to pay for barrier-free investments by both the non-disabled and the disabled, which could provide policy authorities with useful information on how much investment should be made, and who should bear the financial and tax burdens.

\section{OVERALL SUMMARY}

The above is a brief summary of the chapters in this book, each presenting different views on the evaluation of the social security system in Japan, and various useful policy reforms. I shall not outline general conclusions, but hope that readers will draw their own after reading the content of the book.

Nevertheless, several important remarks can be added, based on my reading of the entire manuscript, which may be a somewhat personally biased view. First, Japan faces a crucial decision: whether to continue with its traditional feature of welfare provision, that is, relying on families and enterprises, or shift to a welfare state in which the public sector plays a major role in welfare provision, or to the American-type self-support and privatization of welfare provision. Which direction the country takes must be decided soon. This requires a careful evaluation of each possible route by specialists, and then the Japanese people can reach a democratic decision based on these evaluations and comprehensive discussions by all fellow citizens. Once the direction is determined, concrete reform policies for each social security program can be proposed fairly easily and precisely because everybody will understand the general principles involved.

Second, there are two conflicting views even in this book about the role of the market mechanism. One view stresses the importance of deregulation policies, and the merit of the market mechanism, in other words, a diminishing role of public sector welfare provision. Thus, a DC type and a funded scheme are preferred in pension programs, for example. It is interesting to note that the great majority of non-Japanese and some Japanese authors prefer these reforms. The other view, which stresses the importance of the public sector, does not advocate the merit of the market mechanism so strongly. Recommendations of public policies for welfare provision are presented by several Japanese authors. The distinction arises from individ- 
ual value judgments, and decisions about welfare provision should be reached according to the majority principle.

The studies included in this volume help us to understand the advantages and disadvantages of the Japanese social security system, and to evaluate various policy reforms. I believe that readers have much to learn from this book, and will obtain useful information on the determination of future policy reforms in social security systems.

\section{REFERENCES}

Tachibanaki, T. (1996a), Wage Determination and Distribution in Japan, Oxford: Oxford University Press.

Tachibanaki, T. (1996b), Public Policies and the Japanese Economy, London: Macmillan.

Tachibanaki, T. (2000), The Economics of a Safety Net, Tokyo: Nihon-keizaishinbunsya (in Japanese).

Tachibanaki, T. (2002), The Economics of Mind in Safety, Tokyo: Iwanami-shoten (in Japanese).

Tachibanaki, T. (2003), 'The role of firms in welfare provisions', in S. Ogura, T. Tachibanaki and D. Wise (eds), Labor Markets and Firm Benefit Policies in Japan and the United States, Chicago: University of Chicago Press, pp. 315-38. 